\title{
Vibration analysis techniques for detecting filler-matrix decohesion in composites
}

\author{
S. Corn* - J.S. Dupuy* — P. Ienny* — L. Daridon** \\ * Ecole des Mines d'Alès \\ 6 avenue de Clavières, 30319 Alès cedex - France \\ Stephane.Corn@mines-ales.fr \\ ** Laboratoire de Mécanique et Génie Civil - Université Montpellier II \\ Pl. Eugène Bataillon, 34095 Montpellier - France
}

\begin{abstract}
RÉSUMÉ. Cette étude propose une comparaison entre deux méthodes pour l'identification de propriétés mécaniques dynamiques d'un matériau composite modèle chargé de billes de verre. Nous quantifions également l'influence de la qualité de l'interface charge-matrice sur les propriétés mécaniques dynamiques du polymère chargé. Les paramètres de comportement élastique et dissipatif sont identifiés à partir d'essais non destructifs. Les techniques vibratoires utilisées sont l'analyse modale et l'analyse mécanique dynamique. Nous avons utilisé ces techniques afin de couvrir un très grand spectre de longueur d'onde pour le chargement dynamique.

ABSTRACT This study proposes a comparison between two methods for the identification of dynamic mechanical properties of a composite material model charged with glass beads. We also quantify the influence of the quality of filler-matrix interface on the dynamic mechanical properties of the charged polymer. The elastic and dissipative behavior parameters are identified from non-destructive tests. The vibration techniques used are modal analysis and dynamic mechanical analysis. We used these techniques in order to cover a very large wavelength spectrum for the dynamic loading.
\end{abstract}

MOTS-CLÉS: Matériau composite, endommagement, vibrations, analyse modale, amortissement, facteur de perte, méthode de caractérisation non destructive.

KEYWORDS: Composite materials, damage, vibrations, modal analysis, damping, loss factor, non-destructive testing. 


\section{Introduction}

Characterizing elastic and damping properties of composite material is of growing interest due to the intensive current use of these materials in many of today's engineering components such as aerospace elements, automotive parts (M'Paly, 1998), and other elements submitted to significant dynamic loads. It is well known that dynamic loadings on this type of material induce microstructural damage such as matrix-filler debonding (Mateille et al., 2009(a) and (b)). Composite organic matrices elastic and damping properties are mainly due to viscoelastic behavior of the matrix and of the filler-matrix interface quality. Classically, it is assumed that these mechanical properties of these composites depend more or less on the loading excitation frequency (Kwak et al., 2001), (Oyadiji et al., 1994) and temperature. Elastic static properties of composites can be easily determined by standard quasistatic tests. A complete and satisfactory understanding of viscoelastic composite behavior requires the use of dynamic testing over a wide range of frequencies (or time) and temperatures (Gibson, 2000). This leads using several experimental methods, including static creep tests, relaxation tests and dynamic tests.

In this paper, we focus on the dynamic response of a model composite material in order to observe the influence of the bonding between filler and matrix on the dynamic mechanical characteristics. We use different surface treatments of incorporated particles (glass beads) in order to simulate damage by debonding (Gibson et al., 1998). First of all, we propose a comparison between Dynamic Mechanical Analysis, commonly referred as DMA, and Modal Analysis, commonly referred as $M A$, to characterize PMMA mechanical properties. The purpose of this first study is to calibrate and validate experimental devices and to show how both of these methods are complementary for analyzing a wide range of frequencies. Dynamic modulus and damping ratio obtained from DMA are correlated with impact test data, $M A$. Then we propose a parametric study based on the use of DMA to explore the influence of the surface treatment on both conservative modulus and loss factor. Bad cohesion between filler and matrix can lead to friction phenomena, which tend to increase the damping level of the dynamic response.

\section{Dynamic analyses - experimental and computational setups}

Many authors have discussed the problem of viscoelastic properties identification from vibration measurements. For example, in (Soula et al., 1997), an inversion method adapted to wide frequency bands has been proposed and validated by experimental results on elastomers. (Pintelon et al., 2004) and (Caracciolo et al., 2004) present experimental methods for characterizing viscoelastic materials based on dynamic analysis of beams. (Kergourlay, 2004) has focused on the identification of mechanical damping for these materials. One classical experimental method we have used is the dynamic mechanical analysis (DMA). It involves bending, tension or torsion mechanical tests on specimen submitted to harmonic loads "outside 
resonances". These tests require standard geometries. They are rather expensive and time consuming. A second method, modal analysis, is based on a much simpler experimental device (impact hammer or electrodynamic shaker). It leads to the extraction of modal parameters from the analysis of frequency response functions (FRF) and resonance modes of a structure (Piranda, 2001) (Chevalier, 2002). Identification of mechanical parameters (elastic modulus and modal damping ratio) is achieved by model updating. Post processing of experimental results may however necessitate finite element modeling in case of complex geometry. An intercomparison of these methods (Dupuy et al., 2007) for homogeneous materials has been performed. Modal analysis results obtained for PMMA are presented in this paper.

\subsection{Dynamic mechanical analysis}

DMA measures mechanical properties of a material as a function of time, temperature and frequency. This is a classical analysis technique for polymer characterization. In material science, DMA is mainly used for characterizing a viscoelastic material in terms of temperature (at one fixed frequency), and for determining different relaxation phases of polymer materials. In this study, DMA has been used to estimate the complex dynamic modulus and loss factor of a small beam-like specimen as a function of frequencies at room temperature. Samples are analyzed with two experimental DMA devices (flexural and torsional tests) to compare dynamic properties on large frequency range. This technique is interesting because it enables to analyze frequencies out of resonances, somewhat smaller than the fundamental mode of the sample. This experimental method is limited to low frequencies; the maximum frequency depends directly on the sample stiffness.

For DMA measurements, cyclic loading is applied to the material sample. The complex modulus can be written as:

$$
E^{*}=E^{\prime}+i E^{\prime \prime}
$$

in which $E^{\prime}$ is the storage modulus (real part), showing material elastic behavior (i.e. ratio between stress and strain), and $E^{\prime \prime}$ the loss modulus (imaginary part), which is related to viscoelastic behavior.

For torsional test, the storage and loss shear modulus of viscoelastic material, which will be directly measured, are written as:

$$
G^{\prime}=\cos (\delta) \frac{M L}{J \theta}
$$

where $J$ is the torsion constant $\left(\mathrm{m}^{4}\right), \theta$ is the resulting angle of twist (rad), $L$ represents the sample length (m), and $M$ is the applied loading torque (N.m). 
Damping is expressed in terms of loss factor $\eta$ and is related to amount of energy the material can dissipate. This corresponds to a phase shift angle $\delta$, related to response delay upon excitation, which is defined by :

$$
\eta=\tan (\delta)=\frac{E^{\prime \prime}}{E^{\prime}}=\frac{G^{\prime \prime}}{G^{\prime}}
$$

The damping is due to the viscous behavior of material and we consider it as a structural damping. The theoretical principle, presented here, is valid whatever the method of loading used in DMA device.

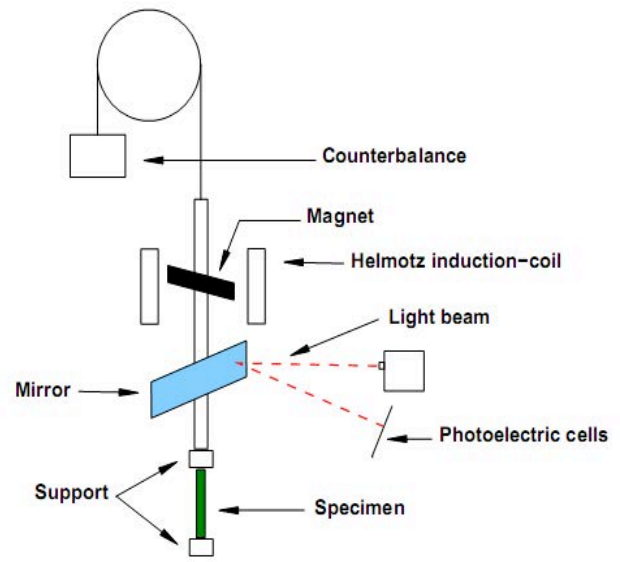

(a) Torsional test

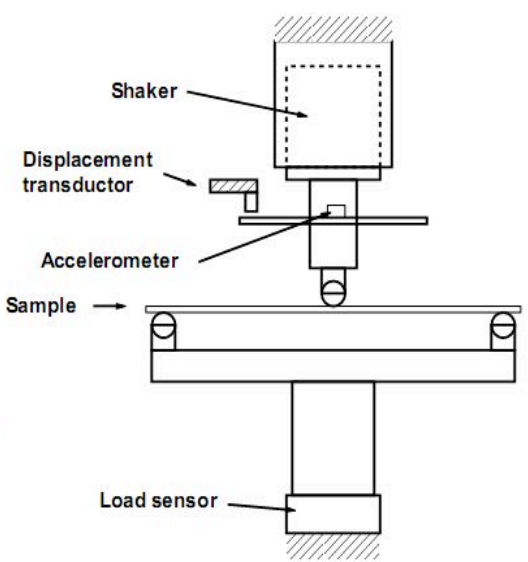

(b) Flexural test

Figure 1. DMA devices, ARES (a) and VA2000 (b)

One device used is a torsional system named ARES (Advanced Rheometric Expansion System), which is manufactured by Rheometric Scientific. Most of the work has been carried out on this experimental setup, shown in figure 1(a). This setup is based on a torsional pendulum test. The sample can be driven at frequencies between $10^{-5}$ and $80 \mathrm{~Hz}$ which provides a large frequency range for measurements. But actually, the efficient range of scanned frequencies depends directly on sample stiffness and test temperature.

The second experimental setup, used in the study to investigate low frequencies, is a Dynamic Mechanical Analyzer VA2000 developed by Metravib. This device, whose principle is shown in figure 1(b), allows to test by bending a simplysupported beam with a concentrated dynamic displacement in the middle. The distance between supports is fixed to $45 \mathrm{~mm}$. Harmonic displacement is applied to the sample by an electro-dynamic shaker, whose set point is given in increments of frequencies (each $5 \mathrm{~Hz}$ ). This displacement is measured and checked by two different sensors. In low frequencies from 5 to $125 \mathrm{~Hz}$, an eddy current displacement 
sensor is used. Then an accelerometer takes over the displacement measurement from $125 \mathrm{~Hz}$ till maximum frequency. Harmonic load response is measured by a load sensor with a nominal capacity of $150 \mathrm{~N}$ and a resolution of $0.1 \mathrm{~N}$.

In this study, PMMA material is investigated on large frequency range between 0.01 and $500 \mathrm{~Hz}$. Variation of $E^{\prime}$ and $\eta$ measured by the two viscoanalyzers are directly compared on graphs figure 2 , showing their strong frequency dependency. It can be noticed that the storage modulus increases from $3.2 \mathrm{GPa}$ at $0.01 \mathrm{~Hz}$ to 4.3 $\mathrm{GPa}$ at $10 \mathrm{~Hz}$ for ARES. The loss factor measured with this test increases sharply with frequency until it reaches to a maximum of $7.5 \%$ at $3 \mathrm{~Hz}$, and then decreases gradually to approximately $7 \%$ at $10 \mathrm{~Hz}$. These results are in a good agreement with classical results for PMMA. With VA2000, the storage modulus $E^{\prime}$ for increases quickly as frequency increases and reaches a maximum value of $6.5 \mathrm{GPa}$ at $500 \mathrm{~Hz}$. The estimated loss factor decreases with frequency to reach $6.4 \%$. Some significant difference appears between ARES and VA2000 results. This is possibly due to misestimating of VA2000 complex stiffness during calibration stage.

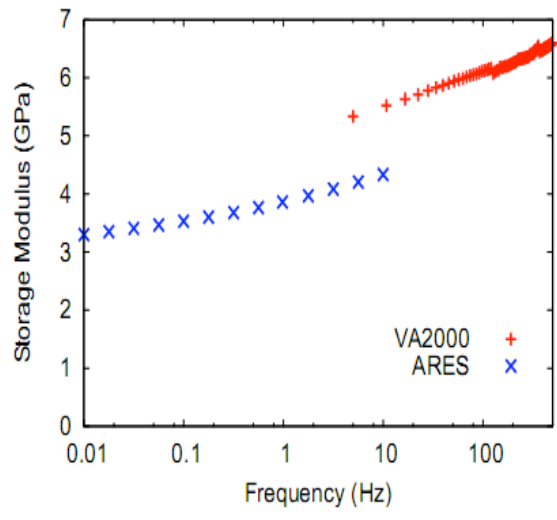

(a)

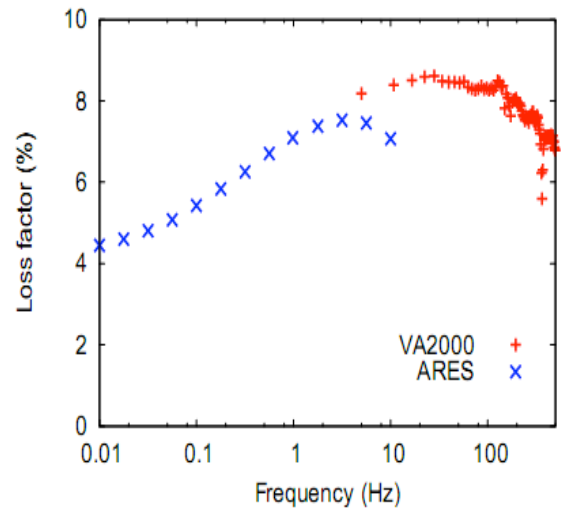

(b)

Figure 2. DMA results, comparison between ARES and VA2000

\subsection{Modal analysis}

Modal vibration tests allow measurement of eigen modes of a structure. They are related to structure stiffness, density and boundary conditions. Each mode is defined by natural frequency, modal damping and mode shape. These dynamic properties are estimated quite directly from the frequency response functions (FRFs) aided by a modal analysis software. PMMA specimens, with various geometries and different sizes, are analyzed this way by using two different experimental setups (impact test and shaker system) for comparison. These modal techniques are used on wide 
frequency range, from 100 to $2000 \mathrm{~Hz}$. Variations of sample shape and dimensions enable to increase number of modes measured over the frequency range of interest.

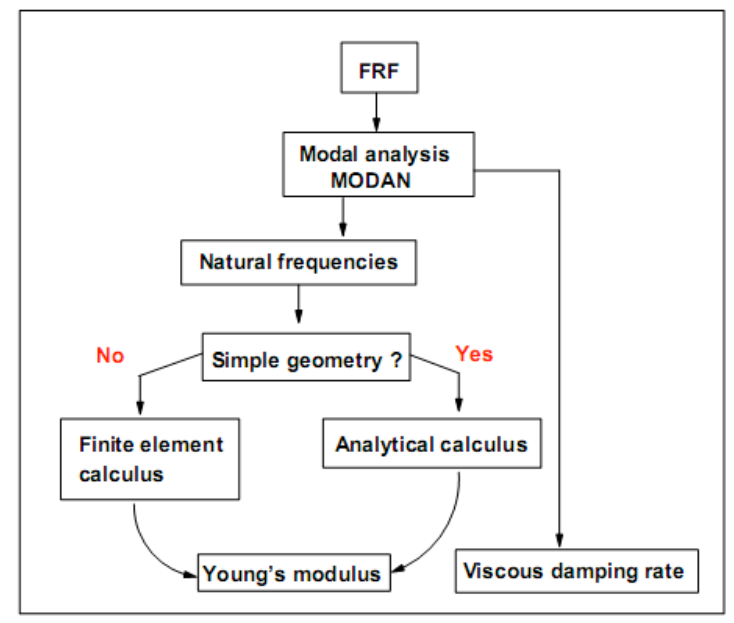

Figure 3. Diagram of modal analysis procedure

Response model consists in a set of frequency response functions (FRF) which are defined over the frequency range. FRF is a fundamental measurement that isolates inherent dynamic properties of a mechanical structure and describes inputoutput relationship between two points on the structure as a complex valued in terms of frequencies. Experimental modal parameters (frequency and damping) are collected from a set of FRF measurements. We use a modal analysis software (MODAN, [5]) in order to extract natural frequency and viscous damping ratio at each resonance (corresponding to magnitude peak of FRF), noted respectively $f_{\text {rexp }}$ and $\xi_{\text {rexp }}$. Theoretically, it is well known that at resonance frequency $f_{r}$ (corresponding pulsation $\omega_{r}$ ), damping ratio $\xi$ is related to loss factor $\eta$ :

$$
\eta\left(\omega_{r}\right)=2 \xi\left(\omega_{r}\right)
$$

Elastic modulus $E_{r}$ is obtained (one value for each measured resonance frequency) using an analytical model or a finite elements modal analysis (ANSYS). The choice depends mainly of structure complexity; as an example, analytical model is available for a beam or a disc, and FE model updating is used for more complicated geometry. 


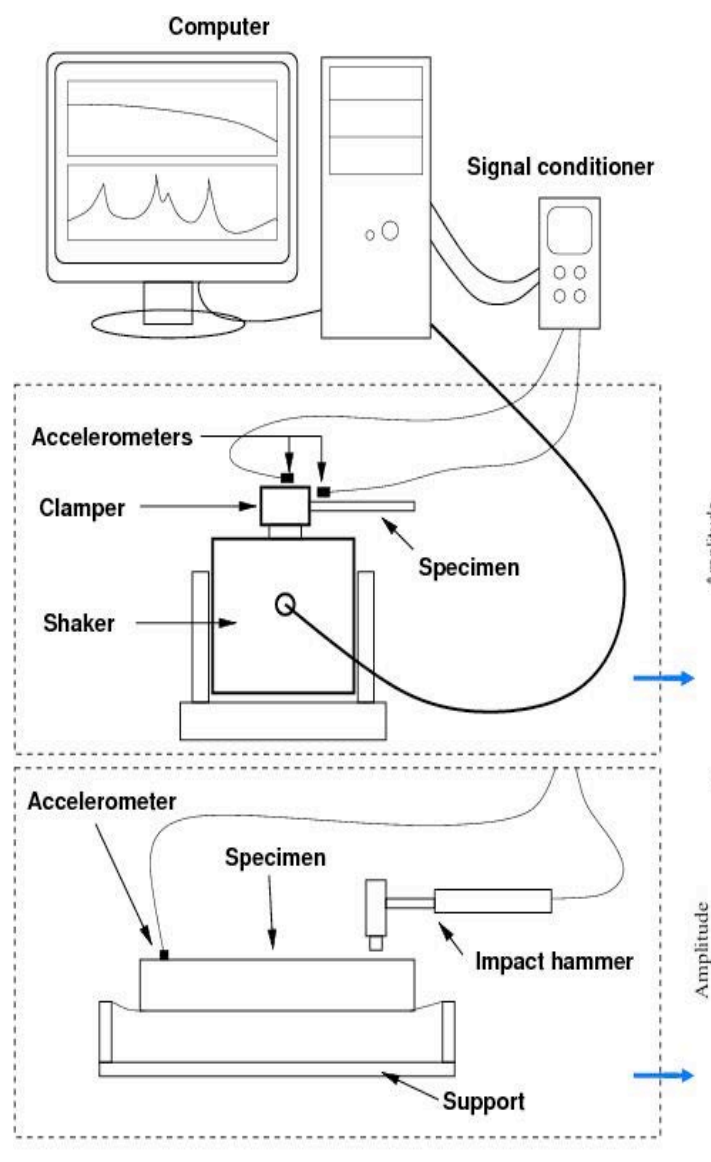

\section{Frequency Response Function}

(FRF)
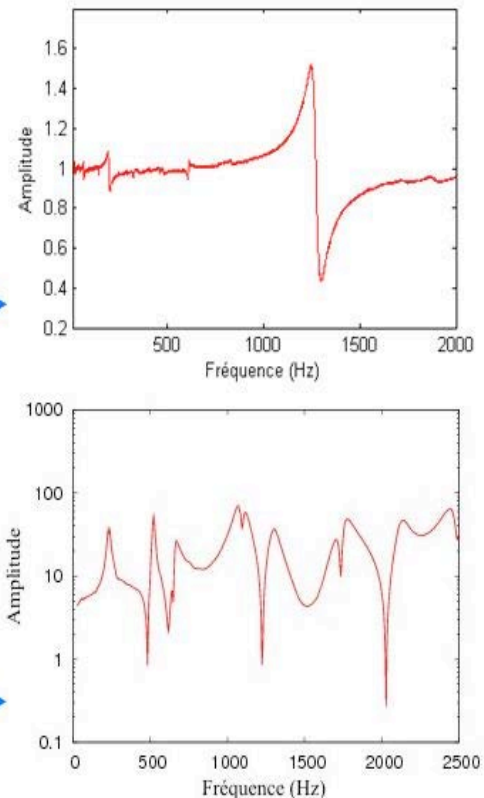

Figure 4. Modal analysis tests: experimental setups and Frequency Response Functions (FRF)

\subsubsection{Shaker test}

A schematic experimental setup, designed to measure FRF of cantilever beam specimen, is shown figure 4 . One end of a beam-like specimen is clamped on shaker system, which provides excitation, while other end is free. Excitation source signal comes from card generator coupled with software, then is increased by amplifier (LDS PA100E-CE). This electrodynamic shaker, LDS V406, produces a vertical sine-sweep force. In this procedure, we use two piezoelectric accelerometer sensors (Kistler 8732A500) which measure vertical acceleration, for one, near clamped end beam, for other, on clamped system to provide a reference signal. Accelerometer position on sample was chosen in order to limit the influence of its mass on dynamic properties. Acceleration signals go through signal conditioner then are picked up by 
acquisition card (NI-4552). PC directs acquisition card and performs data acquisition. Measured response signals are transformed in frequency spectrum using FFT analysis. We obtain one FRF, and then we use modal analysis software MODAN (Piranda, 2001) to extract natural frequencies and viscous damping ratios.

\subsubsection{Impact test}

This technique is fast and inexpensive and can be used for any specimen geometries. An apparatus for impulse-response testing of specimens is shown schematically figure 4. Specimen is excited by impact hammer (Kistler 9722A2000) with a mass of $0.1 \mathrm{~kg}$, while response measurements are collected by an accelerometer fixed on the sample. Thereby, signals acquisition enables to calculate FRF (by FFT). Experimental modal parameters (natural frequencies and viscous damping ratio) are also obtained with MODAN from set of FRF measurements. Procedure to extract elastic modulus is similar to the shaker method. It is determined from analytic model for a simple geometry, or numerical model for complex geometry. Boundary conditions of tested specimens are considered as free. Several geometries have been tested in order to obtain a large range of natural frequencies. Thus, impact test results are considered as a reference, because there is no influence of experimental setup. However, impact tests cannot easily investigate low frequencies (below $100 \mathrm{~Hz}$ ).

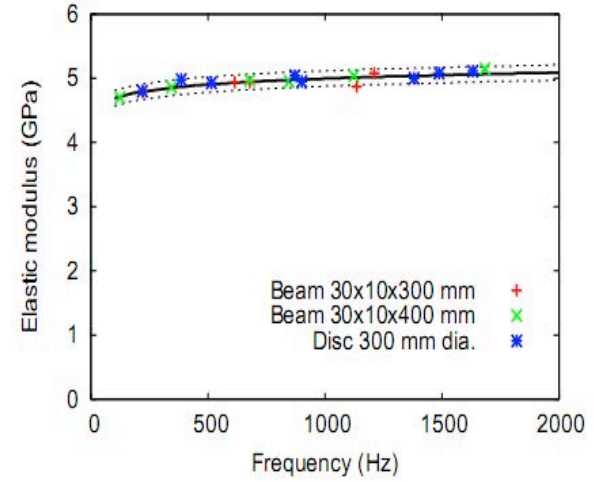

(a)

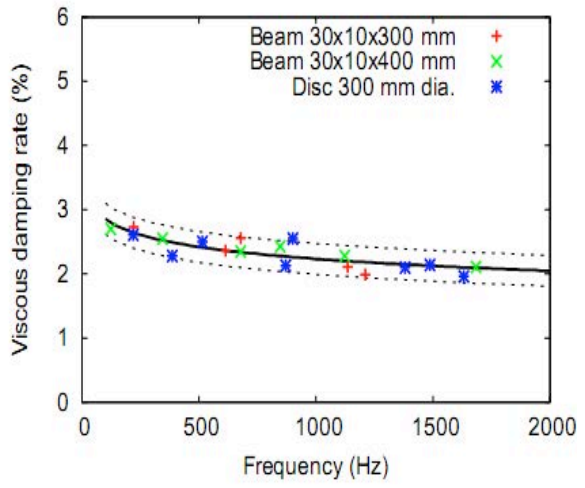

(b)

Figure 5. Elastic modulus and viscous damping ratio of PMMA, with impact test

Experimental results obtained using impact tests for PMMA samples with various geometries are shown figure 5. PMMA elastic modulus increases with frequency, and reaches its maximum of $5 \mathrm{GPa}$ at a frequency of $2000 \mathrm{~Hz}$. Figure 5b shows that estimated viscous damping ratio decreases with frequency for reaching $2 \%$. Indeed, measurement quality is rather good. Error (standard deviation) is namely $0.12 \mathrm{GPa}$ for elastic modulus and $0.24 \%$ for damping ratio. 


\subsection{Comparison of DMA and Modal analysis results}

For comparison of the dynamic methods, values from both measurements are presented figures 6 and 7. Those diagrams show evolution of elastic modulus (or storage modulus) and loss factor as function of frequency solicitations.

Tensile test has also been done on ZWICK Z-010 testing frame, at $1 \mathrm{~mm} . \mathrm{min}-1$ for measurement of PMMA Young's modulus. Tensile modulus $E$ is obtained from the normalized specimens, according to ISO 527 standard. Tensile modulus obtained for PMMA is $3.25( \pm 0.50) \mathrm{GPa}$. This result is spotted on figure 6 for a frequency (or speed) nearly $0.03 \mathrm{~Hz}$. This "quasi-static" value is very close to that obtained with the ARES DMA device.

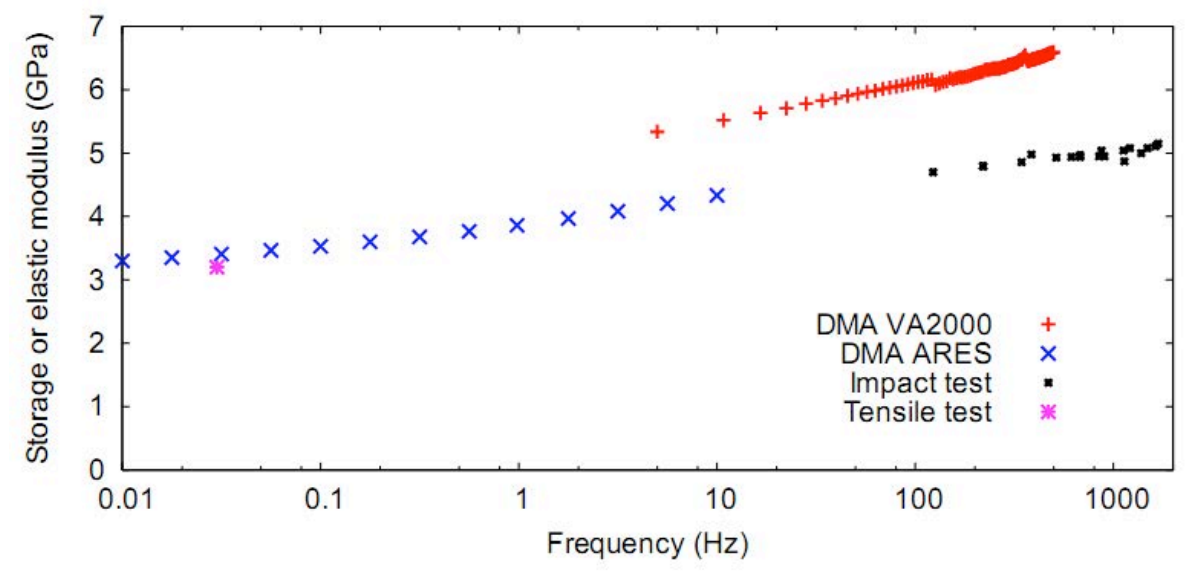

Figure 6. Storage modulus E' versus frequency and elastic modulus E, for PMMA

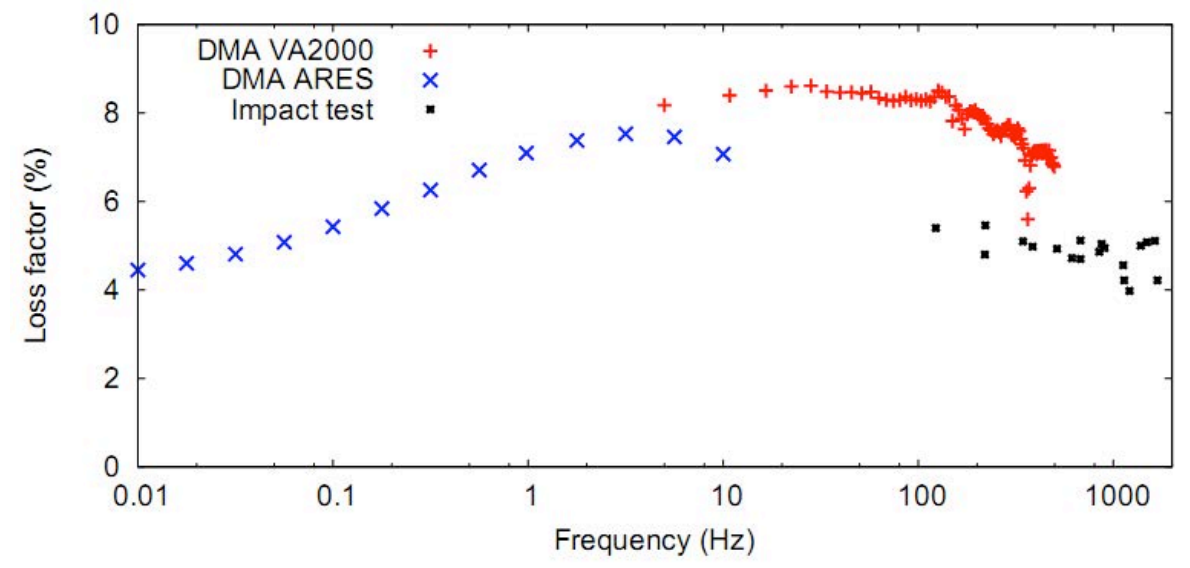

Figure 7. Loss factor versus frequency, for PMMA 
Combination of different analysis methods accounts for viscoelastic behavior of PMMA matrix. The variation of elastic modulus (or storage modulus) and loss factor are followed over a wide frequency range of 0.01 to $2000 \mathrm{~Hz}$. On one hand, DMA methods provide much information on the elastic properties and energy dissipated by the material when it is subjected to mechanical harmonic loading. This method is limited only to low frequencies, due to the influence of the fundamental frequency of samples studied. Different modes of solicitation (bending and torsion) give similar and complementary results. There is some difference for the storage modulus magnitude and loss factor, which is probably due to misestimate of viscoanalyser VA2000 stiffness. On the other hand, dynamic methods based on modal analysis of resonance frequencies, make it possible to cover an important frequency range. For now, the frequency resolution is rather poor, but measurements are much faster than DMA. Comparison of dynamic property evolutions between ARES and modal analysis (impact test) shows complementary results.

\section{Composite materials damage: results and discussion}

The capability of these methods to assess damage of glass particulate composites, simulated by varying adhesion between fillers and polymer matrix, is then studied. It has been shown that damping may be considered as an indicator of dissipation phenomena occurring at different scales (Panteliou et al., 2001). Several cohesion levels have been modeled by varying the grade of the fillers coating. Therefore, some design parameters, such as the type of coating, the volume fraction of fillers and their size distribution, have been adjusted.

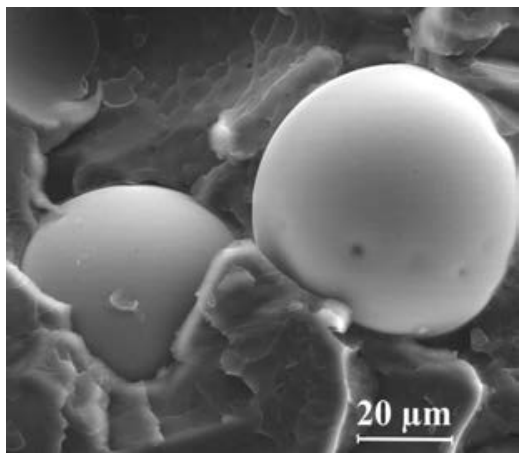

(a)

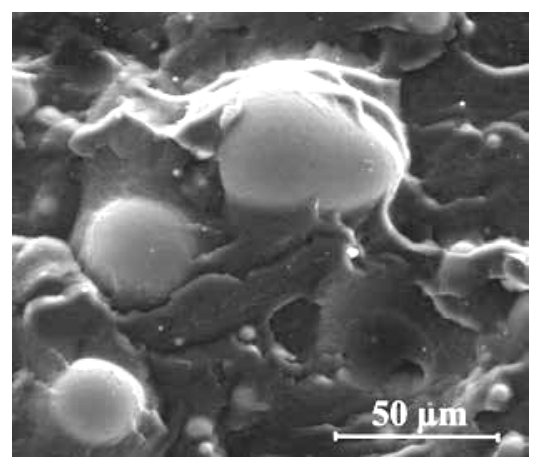

(b)

Figure 8. SEM views of glass beads inclusions in PMMA matrix: without coupling agent ( $a$ ) and with a coupling agent $(b)$ 
For example, DMA measurements obtained for these composite materials are presented figure 9 .
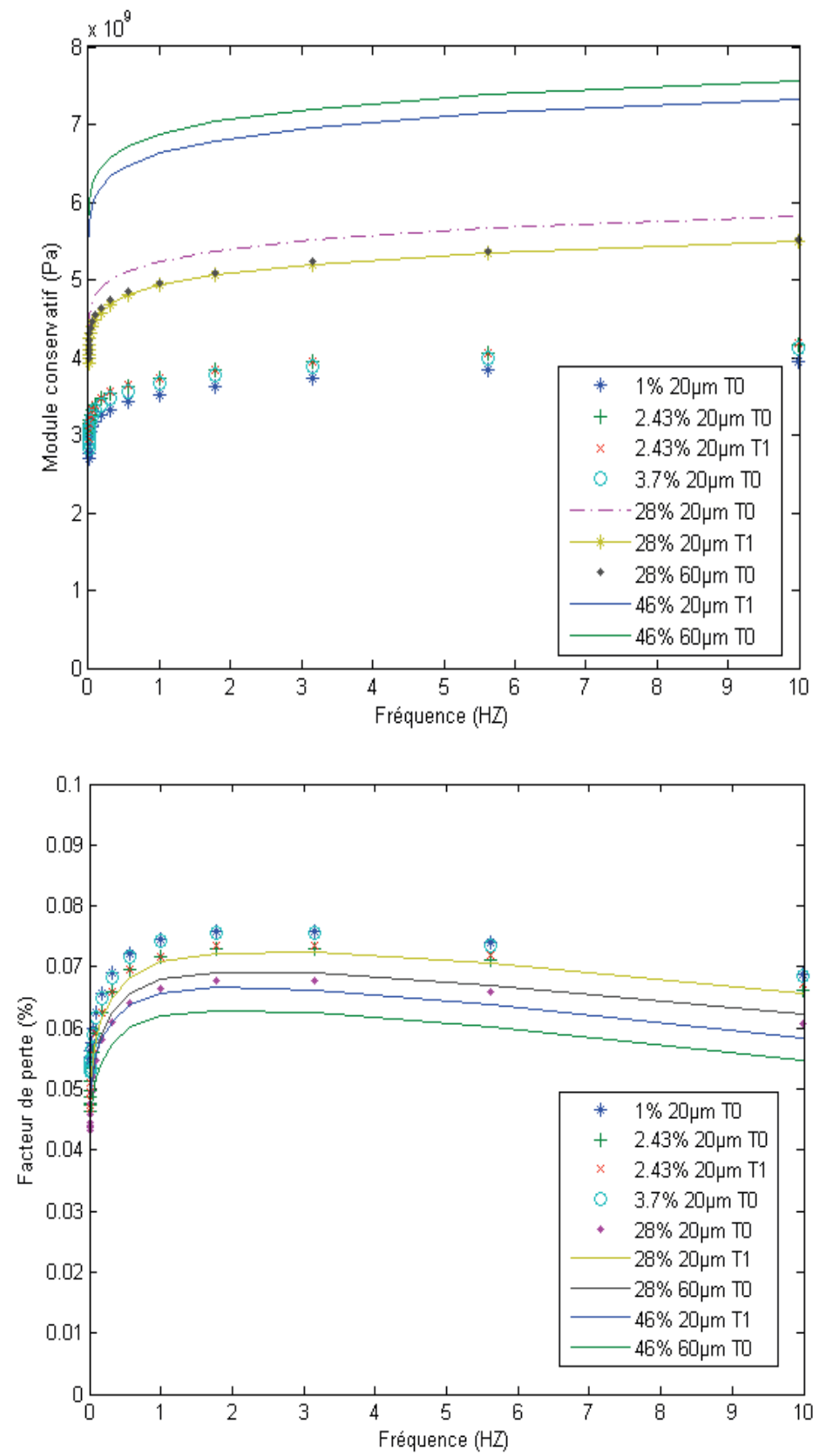
Figure 9. DMA measurements of elastic modulus and loss factor for glass-PMMA composites, for two size distributions (mean diameter $20 \mu \mathrm{m}$ and $60 \mu \mathrm{m}$ ), two types of coating (T0: non cohesive,T1: cohesive), and several volume fractions

The effects on the dissipative response have been studied. The conclusions rely on a comparison with simple analytical homogenization models (Dupuy, 2008). It allows correlating dynamic response, cohesion level and loading mode. The results show a dependence of elastic properties to the volume fraction of fillers in the material. But the measured elastic moduli are not modified by the size of glass beads nor the nature of surface treatments.
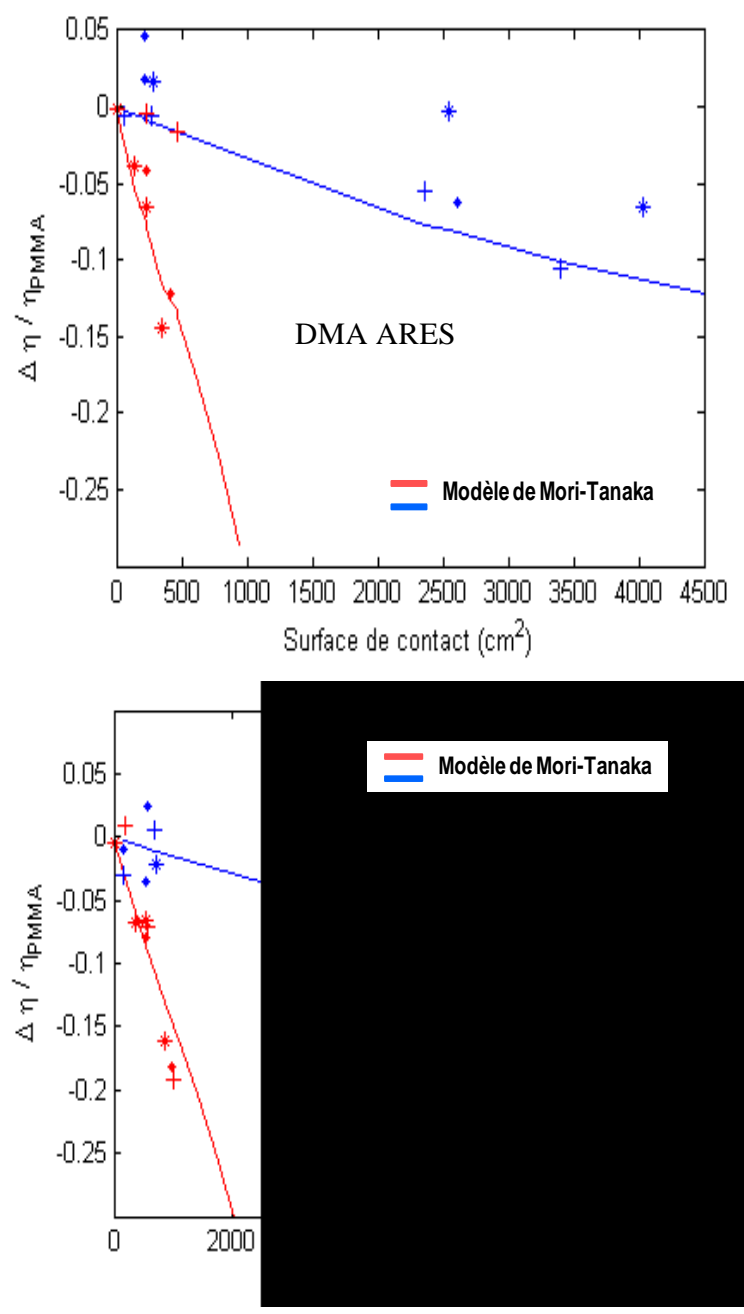
Figure 10. Relative variation of loss factor versus contact surface, measured in DMA ARES and Modal analysis, for a given frequency, particle size $20 \mu \mathrm{m}$ in blue and red size $60 \mu \mathrm{m}$, different coatings $(+\mathrm{TO}, \mathrm{T1} * \mathrm{T2}$ ), with Mori-Tanaka homogenization model (in solid line)

Measurements of loss factors obtained by DMA and modal analysis show a slight increase of the energy dissipation versus contact surface, compared to the cohesive Mori-Tanaka homogenization model (Mori et al., 1973). These results are obtained regardless of the particles size studied and whatever the surface treatment used. However, the analysis of dissipative phenomena induced need for a more accurate modeling of the viscoelastic behavior of particulate composite.

\section{Conclusions}

A Dynamic Mechanical Analyzer was used for testing small rectangular samples in sweep frequency mode. Two experimental devices, which differ by the type of excitation (see section 2.1 for details), contribute to characterize polymer mechanically. They allow to identify the dynamic modulus and the damping ratio, for a wide range of harmonic loads $(0.01$ to $500 \mathrm{~Hz})$. Results obtained for a PMMA material show a strong frequency dependency of the storage modulus which increases from 3.2 GPa at low frequency to $6.5 \mathrm{GPa}$ at high frequency. The loss factor increases to reach to a maximum of $7.5 \%$ at $3 \mathrm{~Hz}$, and then decreases gradually. Parallel tests of modal analysis were conducted with various specimen geometries by using two different experimental setups (impact test and shaker system). Additional results obtained with these second series of tests, based on resonance frequency analysis, make it possible to cover an important frequency range of 0.01 to $2000 \mathrm{~Hz}$. All results obtained for the PMMA material with both methods are in good agreement.

The capability of these methods to assess damage of glass particulate composites is then studied. Model composites, based on glass beads incorporated in PMMA matrix, have been processed to evaluate the influence of design parameters such as the cohesion level (given by various particles coatings), the volume fraction and the size distribution of fillers. Dissipative response, based on DMA experiments, is in good agreement with analytical homogenization models. Results show a dependency of elastic modulus to the volume fraction of fillers but no sensitivity was observed with the size of particles or its cohesion level with the polymer matrix. The loss factors obtained with both methods (DMA and MA) shows a slight increase of the dissipative energy with the contact surface which could be due to frictional phenomena between fillers and matrix. These first results, although encouraging, show the requirement of more accurate results in order to identify analytical modeling. 


\section{References}

Caracciolo R., Gasparetto A., et Giovagnoni M., "An experimental technique for complete dynamic characterization of a viscoelastic material", Journal of Sound and Vibration, Vol. 272, Issues 3-5, p. 1013-1032, 2004.

Chevalier Y., Essais dynamiques sur composites - Caractérisation aux basses fréquences, Techniques de l'Ingénieur, Traité Plastiques et Composites, [AM5400], 2002.

Dupuy J.S., Identification des propriétés mécaniques de matériaux composites par analyse vibratoire, Thèse, Université de Montpellier, 2008.

Dupuy J.S., Ienny P., Corn S., Daridon L., “Comparaison de méthodes dynamiques d'analyse du comportement mécanique de matériaux", 18ème Congrès Français de Mécanique, Grenoble, 2007.

Gibson R.F., "Modal vibration response measurements for characterization of composite materials and structures", Composites Science and Technology, 60:2769-2780, 2000.

Kergourlay G., Mesure et prédiction vibroacoustique de structures viscoélastiques Application à une enceinte acoustique, Thèse, Ecole Centrale Paris, 2004.

Kwak G. H., Inoue K., Tominaga Y., Asai S., and Sumita M.. "Characterization of the vibrational damping loss factor and viscoelastic properties of ethylene-propylene rubbers reinforced with micro-scale fillers", Journal of Applied Polymer Science, 82:3058--3066, 2001.

Mori T., Tanaka K., "Average stress in matrix and average elastic energy of materials with misfitting inclusions", Acta Metallurgica, Vol. 21, Issue 5, p. 571-574, 1973.

Mateille P., Daridon L., Arnould O., Fanget A., Lapebie E., "Mise en œuvre expérimentale d'impacts basse vitesse sur matériau énergétique", 19ème Congrès Français de Mécanique, Marseille, 2009.

Mateille P., Coussy S., Daridon L., Arnould O., Fanget A., Lapebie E., Dymat 2009: 9th International conference on the mechanical and physical behaviour of material under dynamic loading. SEP 07-11, 2009 Royal Mil Acad, Brussels, Belgium.

M'Paly D., Characterization of viscoelastic materials with the aid of experimental modal analysis. PhD thesis, University of Mans, France, 1998.

Oyadiji O., Tomlinson G. R., "Characterization of the dynamic properties of viscoelastic elements by the direct stiffness and master curve methodologies, part 1: design of load frame and fixtures". Journal of Sound and Vibration, 186:623-647, 1994.

Panteliou S. D., Chondros T. G., Argyrakis V. C. et Dimarogonas A. D., "Damping factor as an indicator of crack severity", Journal of Sound and Vibration, Vol. 241, Issue 2, p. 235245, 2001.

Pintelon R., Guillaume P., Vanlanduit S., De Belder K. et Rolain Y., "Identification of Young's modulus from broadband modal analysis experiments," Mechanical Systems and Signal Processing, Vol. 18, Issue 4, p. 699-726, 2004.

Piranda J., Analyse modale expérimentale, Techniques de l'Ingénieur, Traité Bruit et vibrations, [R6180], 2001. 
Soula M., Vinh T., Chevalier Y., Beda T. et Esteoule C., "Measurements of isothermal complex moduli of viscoelastic materials over a large range of frequencies", Journal of Sound and Vibration, Vol. 205, Issue 2, p. 167-184, 1997. 